\title{
Practical Research on Online and Offline Teaching - Taking Baoshan University in Yunnan Province as an Example
}

\author{
Qing Li', Yun Song2* \\ ${ }^{1}$ Baoshan University, Baoshan 678000, Yunnan Province, China \\ ${ }^{2}$ Aba Teachers University, Aba 623002, Sichuan Province, China \\ *Corresponding author: Yun Song, 22595783@qq.com
}

\begin{abstract}
Online teaching has both opportunities and challenges. The main issues that are emphasized in this study is on how to grasp and adapt to the situation, strengthen training and policy incentives, establish quality assurance supervision and inspection as well as linkage mechanism, and actively explore the reform mode. From the perspective of management, taking Baoshan University in Yunnan Province as an example, this article summarizes the practical experience of online teaching, analyzes the shortcomings of online teaching, explores the online and offline hybrid teaching, and promotes local colleges to reform their teaching mode.
\end{abstract}

Keywords: Hybrid teaching; Teaching mode reform; Practical research

Publication date: August 2021; Online publication: August 30, 2021

\section{Introduction}

Modern teaching and high-quality teaching resources cannot be separated from the network, while the law of teaching and students' growth as well as success cannot be separated from the characteristics of the times. In the new era, college students grow in an intelligent environment full of information, thus their cognition is globalized, three-dimensional, and diversified. Colleges and universities survive under the requirements of smart campus, smart classroom, intelligent management, as well as digital colleges and universities. The governance of colleges and universities requires the reflection of modernization, regionalization, and international outlook. With the development of the society, a large number of high-quality teaching platforms are in competition, which further breaks the inherent mode of traditional teaching but contributes to teaching ideas.

In May 2014, the Ministry of Education in China and NetEase jointly launched a MOOC (massive open online course) platform with China's independent intellectual property rights - Chinese University MOOC. MOOC is highly expected by governments all over the world. David Willetts, the British Minister of State for Universities and Science, hopes that the establishment of e-learning platforms would be able to maintain Britain's position in the global competition of higher education. On the other hand, the former president of the United States, Barack Obama, hopes that MOOC, which is a "trend of innovation," can reduce the cost of education while maintaining high quality. For example, the number of MOOC students enrolled in Harvard University in one year has exceeded the total number of students in 377 years of history $[1,2]$.

Schools, teachers, and students are more deeply aware of the connotation and significance of the integration of modern teaching and information technology, which has completely changed the current 
situation of the teaching mode reform and expediated the pace of the reform to a certain extent. At this stage, it is imperative to explore the combination of the online and offline teaching. The concept of reconstruction integration innovation has become a new direction for many educators. From the exploration and practice of online teaching at the school level under the influence of the external environment along with actual teaching effects, this paper analyzes the actual problems of the current online teaching, summarizes practical experiences, explores the online and offline hybrid teaching, and promotes local colleges to create conditions to reform their teaching mode.

\section{Exploration and practice of online teaching in Baoshan University}

The online teaching in Baoshan university aims to stabilize the teaching order, promote the reform of teaching methods, and ensure the teaching quality.

\subsection{Actively respond to the requirements and formulate the adjustment plan of teaching work}

At present, Baoshan University is actively promoting online teaching. Along with the requirements of "one school, one policy" from the national and provincial education departments, the online teaching plan of theoretical courses has been formulated, and supplementary courses including experiments, practical training courses, physical education, and general elective courses have been arranged. At the same time, the guidance for graduates' papers should be strengthened to ensure that the quality of both online and offline guidance are substantially equivalent.

In order to carry out online teaching in a solid and orderly manner, strictly implement the online preparatory teaching scheme, scientifically formulate a course teaching schedule, reasonably plan online and offline teaching contents as well as class periods distribution after students return to school and improve the process assessment and performance evaluation scheme.

On the basis of preliminary preparations, online teaching platforms and curriculum resources should be introduced through multiple channels and teachers should be encouraged to select auxiliary teaching platforms to accomplish their teaching work according to their disciplines and specialties. In addition, the adaptability and identity of teachers' online preparatory teaching and teaching methods should be enhanced. The school's online teaching platform should be used to complete the required work, including data upload, course resource selection, homework guidance, Q\&A (questions and answers), as well as notices and announcements. Teachers should also be encouraged to accomplish supplementary work via these the teaching platform, such as live broadcasting and video recording. In terms of the inspection of teaching effect, the school actively does a good job in online teaching investigation, providing logistics support and technical support, tracking, guiding, and flexibly handling special courses, fully ensuring the teaching effect, as well as promoting the reform of teaching mode.

\subsection{Strengthen technical training and ensure the same direction of guidance and supervision}

Baoshan University have implemented classified guidance for teachers and students. In addition to that, the online training content should be carefully designed while improving the training materials and highlighting the key points as well as the issues. For example, provide training for teachers about course resource upload, release of notice, homework, and discussion topics, self-made course resource selection and link, learning through use, as well as other aspects, whereas for students, provide practical training and set online learning condition questionnaires. It is also necessary to ensure that guidance and supervision are in the same direction, strengthen service awareness, as well as effectively monitor the organization and implementation of network teaching. 


\subsection{Promote models, share experiences, and promote reform}

The school has actively explored and formed a multiplatform integrated teaching mode led by cloud ideological and political education. It has also made every effort to provide high-quality network teaching during the epidemic. Through the selection of 42 excellent teaching cases, the school exchanged 10 excellent teaching cases, the advantages and disadvantages of online teaching have been discussed, and they have contributed rich opinions and suggestions for optimizing the effect of online teaching.

\subsubsection{Achieving high-quality network teaching with cloud ideological and political education}

The school has made a revolutionary exploration of the traditional ideological and political education, in which the classes have been integrated into the cloud and a series of teaching reforms have been carried out, such as flipped classroom. Relying on the school's network teaching platform while making full use of the national high-quality MOOCs of colleges and universities, local high-quality resources such as Baoshan aisqi philosophy, western Yunnan anti-Japanese war culture, and Yang Shanzhou spirit should be developed and utilized according to local conditions in ideological and political education while enhancing the attraction of the course, cultivating students' feelings for their families and country, as well as reflecting the flexibility of the course and the characteristics of the school. Network quality teaching guides students to correctly understand various social phenomena and the practical actions to build a future community in order to strengthen the consciousness of contemporary students in establishing socialist core values.

\subsubsection{Integrate resources on multiple platforms, investigate and analyze the teaching development, as well as create high-quality network teaching}

Along with three major network operators, the school have filed and established cards for 1623 students whose families are facing financial difficulties and have provided these students with $30 \mathrm{~GB}$ data each. At the same time, 476 teachers have been trained in using the network teaching platform, thus forming a teaching mode based on the school's network course platform, expanding and using the platforms of Chinese University MOOC, smart tree, and superstar, as well as assisting the network ladder, micro lecturer cloud platform, WeChat, Tencent, and other network tools. According to statistics, Baoshan University has 534 courses with online teaching, accounting for 58\%; teachers visit accounted for 95,121 times whereas 2,985,660 times reflected the students visit, with a total of 3,080,791 times; 64\% of teachers use two methods for teaching, and $27.7 \%$ of teachers use three or more teaching methods. According to the survey, about $60 \%$ of the students are very satisfied, satisfied, and relatively satisfied with the way and arrangement of e-learning. From the comparison of teachers' requirements between online and offline teaching, 15.5\% felt that online teaching has more requirements than offline teaching.

The issues that students have encountered in online teaching are insufficient classroom interactions between teachers and students as well as the limitations of online guidance. Overall, teachers and students are satisfied with the development of network teaching during this semester.

\section{Shortcomings of online teaching}

Although online teaching has many advantages, it also has many shortcomings. In regard to MOOC, although there is no scale limit for students, there is almost no interaction between teachers and students as well as learning evaluations. There are academic integrity problems. The registration rate is often high, but the success rate is low. With the early online platform teaching practice in Baoshan University, there are many problems that should not be neglected. The first is regarding teaching equipment. It is impossible to carry out an online experimental course teaching. Experimental course requires the use of relevant equipment to complete reports. For online teaching, it is impossible to carry out confirmatory, 
comprehensive, and innovative experiments. The second is the limitation of school-enterprise cooperation. It is impossible for online teaching to provide practical training activities, such as internships and practices, which affects the whole teaching process, especially data acquisition that is required in graduation thesis (design). The third is the acclimatization to foreign things. Some students are unable to adapt to the progress of online teaching. Although high-quality resource courses such as Chinese University MOOC and smart tree can be adopted, some students still find it difficult to understand, especially students in local colleges with poor basic ability. Fourth, it involves monitoring. Several students lack learning initiative and enthusiasm; however, teachers are not able to effectively monitor students' learning dynamics in time and it is difficult to evaluate the teaching effect. The fifth is poor emotional connection. Teachers and students do not have the opportunity to communicate face-to-face. Online teachings usually last for 90 minutes, and it is difficult to ensure the sustainability of focus among teachers and students. Teachers lack a sense of acquisition and satisfaction whereas students lack emotional communication with their teachers. Some students are afraid to ask questions and some refuse to ask, resulting in poor timeliness for problem-solving during class. Sixth, "the new darling of intelligence has little effect". Some senior teachers face obstacles in operating these platforms, completely break the inherent traditional classroom design, and subjectively resist the exploration of new teaching modes. However, there are teachers who are willing to try out new teaching methods. In such cases, the setbacks are the lack of good recording equipment and the use of appropriate recording software, which would delay class hours to a certain extent ${ }^{[3]}$.

\section{Exploration of online and offline hybrid teaching}

\subsection{Consolidate the achievements of online teaching and continuously deepen the construction of curriculum connotation}

The four links which are teaching, learning, management, and supervision would be continuously emphasized. In addition, various online teaching platforms at all levels would be relied on while carrying out online teaching activities with rich contents, diverse forms, and excellent quality. Multiple measures would also be used to strengthen organization and management, monitor the quality of various forms, as well as ensure the smooth and high-quality operation of online teaching. First, it is necessary to strengthen curriculum construction and create first-class courses. The school can invest in the construction and selection of online courses to enhance teachers' enthusiasm for online teaching by rewarding and promoting reform. Second, it is also necessary to strengthen the interaction between teachers and students as well as optimize teaching methods. Teachers should upload learning materials to the network platform in advance, complete course content projects in groups, consciously encourage students to accept and develop an enjoyment for online teaching methods, report projects in offline classes, and analyze them so as to improve students' learning initiative driven by projects. Third, active learning should be stimulated along with strengthening pre-class preview. Online teaching should be used to impart knowledge contents whereas offline teaching should be used for content integration, explanation, group discussion, as well as Q\&A in order to enhance students' sense of urgency and responsibility in learning, in addition to promote the interaction between students and teachers based one the offline traditional method. Fourth, it is necessary to strengthen curriculum supervision as well as provide assistance and guidance. The quality evaluation center of the school should regularly check the online and offline teaching, improve the teaching evaluation mechanism, regularly conduct teaching sharing, provide assistance and guidance on one-to-one or one to many basis for some teachers, encourage teachers and students to actively seek change and provide feedbacks, as well as improve teachers' awareness and concept of classroom teaching revolution. Fifth, the platform construction and management level should be improved. The technical center of the school should ensure the maintenance of the teaching platform, arrange ways to download and use rich teaching resources, 
as well as improve the management service concept and level.

\subsection{Actively explore the reform of teaching mode and effectively promote the quality of classroom teaching to a new level}

Professor Lue from Harvard University believes that if a university is not aware of the reform signal and believes that MOOC is only a video collection of traditional courses, in which the online courses are not fundamentally different from the traditional classroom, there is no doubt that the university will be in danger. Therefore, it is necessary to recognize the essential difference between online teaching and traditional offline teaching, actively explore the reform of the teaching mode, as well as effectively promote the quality of classroom teaching to a new level ${ }^{[1]}$.

The national and provincial "Double 10000 Plan" requires colleges and universities to create a number of online and offline "golden courses" hybrid teaching. Hybrid courses are important for the construction of five types of first-class courses. Colleges and universities should use the reform of the teaching mode as an opportunity to promote the combination of online and offline teaching, guide teachers and students to form habits, promote deeper teaching reforms and the construction of first-class courses, upgrade the quality of classroom teaching to a new level, as well as enhance the competitive advantage of education. First, it is necessary to continue to strengthen the construction of the teaching platform, promote teachers to form high-quality online courses, guide teachers to promote multiplatform classroom teaching, and guide students to scientifically and reasonably use new learning instruments, such as smartphones. Second, excellent online and offline hybrid teaching cases can be accumulated while using exemplary teaching experiences and models for guidance, popularizing them through briefings, presenting awards for online and offline teaching reform achievements, constantly improving teachers' subjective initiative to actively promote the reform of teaching models, as well as striving to produce high-quality teaching achievements. Third, through big data analysis, it is necessary to provide timely feedback on teaching quality, enhance students' learning autonomy and self-discipline, emphasize on improving students' ability in terms of team learning and problem-solving in groups, give full play to the management efficiency of the teaching team and research office team in unified guidance, lesson preparation, lesson evaluation, and progress, as well as stimulate teachers' motivation in the reform of teaching. Fourth, the three figurative players of education which include schools, teachers, and students should actively adapt to teaching arrangements based on the requirements of national policies. In particular, schools should continue with their excellent arrangements in regard to teaching, strengthen the foresight and innovation as well as promote a more scientific and standardized teaching management, formulate online and offline hybrid teaching schemes in line with the actual situation of their schools, and maintain the executive role of teachers and students.

The educational reform with technology transfer as the core finally returns to the application of technology to improve the quality of teaching and learning. It should be studied systematically and deeply to promote the process of thinking, challenge, internalization, and even the generation of new knowledge among learners in order to have a real impact on the current classroom teaching and students' learning in higher education ${ }^{[4,5]}$.

\section{Disclosure statement}

The authors declare that there is no conflict of interest.

\section{References}

[1] New J, 2013, Has President Obama Caught MOOC Fever. eCampus News. https://www.ecampusnews. com/2013/08/23/has-president-obama-actually-caught-mooc-fever/ (updated August 23, 2013). 
[2] Coughlan S, 2013, Harvard Plans to Boldly Go with 'Spocs'. BBC News. https://www.bbc.com/news/ business-24166247 (updated September 24, 2013).

[3] Sidorko PE, 2013, The Access Dunia 2013 Online Conference, October 30, 2013: MOOCs and SPOCs: Where is the Library?, Libraries and Publishing - Evolving in the New Directions. Malaysia Chapter, Penang, Malaysia, 7-8.

[4] Kang Y, 2014, Post MOOC Era of Online Education - SPOC Analysis. Educational Research of Tsinghua University, 35(01).

[5] Li M, Zhang Y, Ye F, et al., 2013, Pedagogical Investigation of Large-Scale Online Open Courses. Tsinghua University Press, Beijing, 113. 